\title{
Comparative Study of Phenolic Profile and Content in Infusions and Concentrated Infusions of Buddleja Scordioides Treated by High-Intensity Pulsed Electric Fields (HiPEF)
}

\author{
Jesús Omar Díaz-Rivas ${ }^{1}$, José Alberto Gallegos-Infante ${ }^{1, *}$, Aurora Valdez-Fragoso ${ }^{2}$, \\ Nuria Elizabeth Rocha-Guzmán ${ }^{1}$, Rubén Francisco González-Laredo ${ }^{1}$, \\ Alfredo Rodríguez-Ramírez ${ }^{1}$, Claudia Ivette Gamboa-Gómez ${ }^{3}$ iD and \\ Martha Rocío Moreno-Jiménez ${ }^{1}$ \\ 1 Tecnológico Nacional de México/Instituto Tecnológico de Durango, Blvd. Felipe Pescador 1830 Ote., \\ 34080 Durango, Dgo., Mexico; omar.diaz1404@gmail.com (J.O.D.-R.); nrocha@itdurango.edu.mx (N.E.R.-G.); \\ gonzalezlaredo@gmail.com (R.F.G.-L.); rodriguezramirez@itdurango.edu.mx (A.R.-R.); \\ rrmm29@yahoo.com.mx (M.R.M.-J.) \\ 2 Centro de Biotecnología FEMSA, Escuela de Ingeniería y Ciencias, Tecnológico de Monterrey, Av. Eugenio \\ Garza Sada 2501 Sur, Col. Tecnológico, 64849 Monterrey, NL, Mexico; avfva@yahoo.com \\ 3 Instituto Mexicano del Seguro Social, Unidad de Investigación Biomédica, 34067 Durango, Dgo., Mexico; \\ clau140382@hotmail.com \\ * Correspondence: agallegos@itdurango.edu.mx; Tel.: +52-618-8185402 (ext. 111)
}

Received: 8 September 2018; Accepted: 22 October 2018; Published: 1 November 2018

\begin{abstract}
The effect of high-intensity pulsed electric fields (HiPEF) has been reported on the microbial resistance of fruit juices and beverages. However, the influence of HiPEF on bioactive compounds in herbal infusions is still limited. The objective of the present work was to evaluate chemical stability of polyphenols of infusions from Buddleja scordioides or Salvilla under thermal processing (concentrates) followed by HiPEF treatments. Buddleja infusions were prepared at $1 \% w / v$ of salvilla, heated, filtered and concentrated in a thin falling film evaporator. Three different HiPEF treatments were applied to Buddleja scordioides concentrated beverages. The percentage of pulse rate was 25 and $90 \%$; output temperature, $18.3 \pm 1{ }^{\circ} \mathrm{C}$; and the frequency range, 100, 300 and $400 \mathrm{~Hz}$. The feed flow was $0.5 \mathrm{~L} / \mathrm{h}$. DPPH radical scavenging assay, inhibition of Nitric Oxide activity and analysis of phenolic acids and flavonoids by UPLC-ESI-MS/MS were determined. ANOVA one-way analysis and Tukey test $(p<0.05)$ were used to analyze results. Concentration process increases the amount of flavonols; however, the use of HiPEF produces a minor reduction on antioxidant capacity. The use of HiPEF at $1000 \mathrm{~kJ} / \mathrm{kg}$ and $1100 \mathrm{~kJ} / \mathrm{kg}$ displays a similar profile on phenolic acids between HiPEF-treated beverages and concentrates, showing that the use of HiPEF may be a promissory technology in the processing practices of herbal infusions.
\end{abstract}

Keywords: Buddleja scordioides; concentrates; herbal infusions; high-intensity pulsed electric fields; Salvilla; stability

\section{Introduction}

An herbal infusion is a beverage obtained from the aerial parts of plants such as grasses, leaves, tree barks or roots, which has been poured into boiling water and let it still for few minutes [1].

In the last decade, consumption of herbal infusions (e.g., green tea, chamomile, etc.) is an increasing prophylactic practice in Mexico and worldwide. In Mexico, at least $37 \%$ of the population 
drinks herbal infusions as alternative medical treatment or for pleasure. In general, herbal infusions are rich in bioactive phytochemicals as polyphenols. These natural compounds share a significant high antioxidant and antiradical potential as deduced from a variety of biochemical methods such as the DPPH or nitric oxide inhibition assays [2-4]. Antioxidants are substances that delay the oxidation process, inhibiting chain reactions initiated by free radicals and playing an important role in chemoprevention [5].

According to Arrieta-Baez et al. [6], one of the most used plant infusions in treatment of intestinal diseases in Mexico is Buddleja scordioides Kunth, commonly known as escobilla, butterfly-bush, mato, salvia real or salvilla. This herb is recommended to prepare infusions with the whole plant, boiling in water or cow milk and giving it to children having stomach aches $[6,7]$.

Several bioactive compounds have been extracted and reported from this plant. Some examples are verbascosides [8], triterpenoid saponins [7] and flavonoids such as rutin, quercetin and quercitrin [9].

The effect of thermal processing on polyphenolic compounds in fruit juices and vegetal beverages has been studied in recent years [10-13]. This effect is very complex, since it is dependent on the beverage type, store conditions, type of compounds present in the beverage, chemical structures, concentration, oxidation-reduction reactions and interactions between molecules. Therefore, the reports of effects of thermal processing on the antioxidant properties and phenolic composition of treated products are not consistent.

Among the flavonoids present in Buddleja, such as quercetin, it has been reported with an increase up to $90 \%$ when treated under pressure at $120^{\circ} \mathrm{C}$ [14]; however, other reports have indicated quercetin degradation in foods treated at $100{ }^{\circ} \mathrm{C}[15,16]$.

It has been observed an increase in concentration of phenolic acids such as coumaric, ferulic or ellagic acids in fruit juices after heating treatments, independently of the fruit type or thermal process [17], while flavonols have not changed [18]. In addition, Arthur et al. [19] treated Lippia by steam pasteurization and reported high thermal stability of verbascosides.

It is important to note differences between fruit juices and herbal infusions. An herbal infusion is fixed from dried or fresh leaves, roots, barks, fruits or seeds and hot water for few minutes. In contrast, fruit juices could be obtained by mechanical pressure to break vegetal cells [1].

Industrial processing of herbal infusions implies operations applied to meet quality standards of the product based on the elimination of microorganisms and inactivation of enzymes to delay the oxidation of beverages. These processes can affect bioactive compounds present in beverages, reducing the functional and nutritional qualities of the final product [20]. As a complement or replacement of the traditional thermal processing of beverages, high-intensity pulsed electric fields (HiPEF) may be considered as a promising non-thermal food preservation technology [21].

HiPEF is one of the most attractive technologies due to its short treatment time and reduction of heating effects with respect to other technologies. The technology of HiPEF allows the inactivation of vegetative cells, bacteria and yeast in various foods. The resistance of bacterial spores to HiPEF has been proven by several authors, because the applications of this technology have focused mainly on pathogenic microorganisms, especially in acidic foods [22].

The processing by HiPEF consists on the application of short-duration electric pulses $(1-10 \mu \mathrm{s})$ and high electric field strengths $(15-40 \mathrm{kV} / \mathrm{cm})$ to foods located between two electrodes, one of which is connected to ground and the other to a high voltage node, producing an electric field in the space in between [23-26]. Many papers have been published on the microbial resistance to HiPEF treatments in fruit juices [24-26]. However, the influence of HiPEF on bioactive compounds of herbal infusions is still limited. Although several authors [27] have evaluated green tea infusions processed by HiPEF and others [28] have shown that use of HiPEF changes individual chemical components present in kombucha beverages, the use of HiPEF for processing herbal infusions is not well known yet.

Therefore, the objective of the present work was to evaluate chemical stability of polyphenols of infusions from Buddleja scordioides under thermal processing (concentrates) followed by high-intensity pulsed electric fields (HiPEF). 


\section{Materials and Methods}

\subsection{Materials}

Formic acid was obtained by Química Monterrey (Monterrey, NL, Mexico), acetone by Scientific CTR (Monterrey, NL, Mexico). The acids 4-hydroxybenzoic, 2,5-dihydroxybenzoic, protocatechuic, caffeic, gallic, chlorogenic, quinic, ferulic, coumaric, vanillic, rosmarinic, caftaric, trans-cinnamic, syringic, ascorbic, sinapic, 4-O-caffeoylquinic, 3,4-di-caffeoylquinic and 4,5-di-O-caffeoylquinic, as well as 2,4,6-trihydroxybenzaldehyde, quercetin, naringenin, naringin, procyanidin B1/B2, gallocatechin, catechin, epicatechin, gallocatechin gallate, epicatechin gallate, quercetin-3-O-glycoside, myricetin, rutin, luteolin, kaempferol, kaempferol-3-O-glycoside, neohesperidin, phlorizin dihydrate, apigenin, phloretin, acacetin and quercetin glucuronide were obtained by Sigma Aldrich (St Louis MO, MI, USA). DPPH (2,2-diphenyl-1-picrylhydrazyl), Folin-Ciocalteu 2N, sodium bicarbonate, acetonitrile and methanol were purchased from Sigma-Aldrich (Toluca, Mexico).

Salvilla (Buddleja scordioides Kunth) was collected in Guadalupe Victoria, Durango, México on the fall of 2016.

\subsection{Methods}

\subsubsection{Salvilla Infusion and Concentrates}

Salvilla infusion was prepared following the procedure described previously [29]. Briefly, an infusion $(20 \mathrm{~L})$ at $1 \% \mathrm{w} / v$ of salvilla was heated at $80{ }^{\circ} \mathrm{C}$ by $10 \mathrm{~min}$; next, the infusion was filtered by using a piece of cotton cloth $\left(1 \mathrm{~m}^{2}\right.$, pore size of $\left.0.5 \mathrm{~mm}\right)$. Obtained infusion was cooled off to room temperature and concentrated in an agitated thin falling film evaporator (APEX, SSE69, Clark, PA, USA) operated at following settings: feed flow of $20 \mathrm{~L} / \mathrm{h}$, vapor pressure of $275.79 \mathrm{kPa}$ and vacuum pressure of $16.93 \mathrm{kPa}$. Concentrated samples were stored at refrigeration conditions before treatment by HiPEF.

\subsubsection{HiPEF Treatment}

HiPEF treatment was performed by the use of ELCRACK-HVP 5, DIL (Quackenbrock, Germany). Buddleja scordioides concentrated beverages were pumped (pump SEEPEX CS, Bottrop, Germany) at one feed flow $(0.5 \mathrm{~L} / \mathrm{h})$ into the two treatment chambers with two stainless steel electrodes (diameter, $5 \mathrm{~mm}$; height, $3 \mathrm{~cm}$; gap, $0.5 \mathrm{~cm}$; volume, $0.196 \mathrm{~mL}$ ). Treatment configuration was in continuous mode, at one step without recirculation (square wave). To control temperature increases during HiPEF processing, cooling water was recirculated (i.e., temperature control was made manually by the use of cold water, cryo-gel bags and recirculation bath). HiPEF-treated concentrated salvilla infusions were collected into sterile glass recipients of one gallon.

Three different HiPEF treatments were applied to Buddleja scordioides concentrated beverages. The percentage of pulse rate applied was 25 and $90 \%$; the output temperature, $18.3 \pm 1{ }^{\circ} \mathrm{C}$; and the frequency range, 100, 300 and $400 \mathrm{~Hz}$. The feed flow was $0.5 \mathrm{~L} / \mathrm{h}$ for all treatments. The initial temperature was $14.5^{\circ} \mathrm{C}$. The electric parameters were monitored by an oscilloscope (Sony-Tektronix tds2022C, Beaverton, OR, USA). The temperature was monitored by a thermocouple (Control Company, Friendswood, TX, USA). The specific energy was obtained following a described method [28]. The details for each treatment are summarized in Table 1.

Table 1. Experimental conditions of the High-Intensity Pulsed Electric Field (HiPEF) treatment applied to concentrated infusions of Buddleja scordioides.

\begin{tabular}{cccc}
\hline Experimental Run & \% pulse & Time $(\boldsymbol{\mu s})$ & Frequency $(\mathbf{H z})$ \\
\hline 1 & 90 & 4 & 100 \\
2 & 25 & 20 & 300 \\
3 & 25 & 20 & 400 \\
\hline
\end{tabular}




\subsubsection{DPPH (2,2-Diphenyl-1-picrylhydrazyl) Radical Assay}

DPPH test was performed by reported methods [29,30]. Briefly, $2990 \mu \mathrm{L}$ of DPPH methanolic solution and $10 \mu \mathrm{L}$ of sample or catechin as standard at $10 \mu \mathrm{g} / \mathrm{mL}$ were mixed; then, samples were read at $515 \mathrm{~nm}$ in a UV/VIS Cary 50 spectrophotometer by $1 \mathrm{~min}$. Results were expressed as \%RSA (radical scavenging activity), obtained by the next linear regression equation:

$$
\% \text { Inhibition }=([\text { Abs }] \text { control }-[\text { Abs }] \text { sample }) /[\text { Abs }] \text { control } \times 100
$$

\subsubsection{Inhibition of Nitric Oxide}

Determination of nitric oxide was done following methodology already described [31]. The absorbance was measured at $546 \mathrm{~nm}$ and results were expressed as \% inhibition, using the following equation:

$\%$ Inhibition $=($ Absorbance of blank - Absorbance of the sample $) /($ Absorbance of blank $) \times 100$

Indomethacin $(2 \mu \mathrm{g} / \mathrm{mL})$ was used as control.

\subsubsection{Analysis of Phenolic Compounds by UPLC-ESI-MS/MS}

Detection and quantification of major compounds was achieved using electrospray ionization/tandem spectrometry in multiple reaction-monitoring mode (MRM). Sample analysis was carried out with an Acquity UPLC system (Waters Corp., Milford, MA, USA) coupled with a tandem Xevo TQ-S triple quadrupole mass spectrometer (Waters Corp., Milford, MA, USA). The LC system consisted of a sample manager $\left(6^{\circ} \mathrm{C}\right)$ and a quaternary solvent manager. The column used to separate the phenolic compounds was a C18, $150 \mathrm{~mm} \times 2.1,1.7 \mu \mathrm{m}$ (Agilent, Santa Clara, CA, USA), operated to $30^{\circ} \mathrm{C}$. The elution profile included two solvents: acidified Milli $Q$ water with $7.5 \mathrm{mM}$ formic acid (Solvent A) and acetonitrile LC-MS (Solvent B): Initial 97\% A, 1.88 min gradient to 91\% $\mathrm{A} ; 5.66$ min gradient to $84 \% \mathrm{~A} ; 16.90$ min gradient to $50 \% \mathrm{~A} ; 19.62$ min gradient to $97 \% \mathrm{~A} ; 20.0 \mathrm{~min}$ $97 \%$ A for column stabilization at a flow rate of $210 \mu \mathrm{L} / \mathrm{min}$. Ionization was carried out using as co-solvent methanol with $0.1 \%$ formic acid $(v / v)$ at a flow of $5 \mu \mathrm{L} / \mathrm{min}$ with the use of an isocratic solvent manager (Waters Corp., Wexford). Multiple reactions ionization mode was used for MS/MS assays. Electrospray ionization (ESI) in negative conditions were as follows: capillary voltage $2.5 \mathrm{kV}$, desolvation temperature $400{ }^{\circ} \mathrm{C}$, source temperature $150{ }^{\circ} \mathrm{C}$, desolvation gas flow $800 \mathrm{~L} / \mathrm{h}$ and cone gas flow $150 \mathrm{~L} / \mathrm{h}$, collision gas flow was $0.13 \mathrm{~mL} / \mathrm{min}$, MS mode collision energy 5.0 and MS/MS mode collision energy 20.0. For identification and quantification of phenolic profile a mixture of standards $(20 \mathrm{ng} / \mu \mathrm{L}$ ) was used for monitoring retention time and $\mathrm{m} / \mathrm{z}$ values and MS/MS transitions. Multiple reaction monitoring mode was recorded for samples and standards. The UPLC and Tandem Xevo TQ-S triple quadrupole mass spectrometer control and data processing was using MassLinx v. 4.1 Software (Waters Corp.).

\subsection{Statistical Analysis}

Data were expressed as mean \pm standard deviation and analyzed by one-way ANOVA to evaluate main effects and Tukey's test to verify differences between means at $\alpha=0.05$.

\section{Results}

\subsection{Physicochemical Parameters}

Physical parameters of infusions, concentrates and HiPEF-treated beverages are shown in Table 2. As expected, solid content present in concentrated infusions was higher than observed in infusions; 
although no statistical differences were observed in the solid content between concentrates and HiPEF-treated concentrates.

Minor changes in $\mathrm{pH}$ were observed in the concentrates and HiPEF-treated concentrated beverages in comparison with the infusions.

Table 2. Solid content (mg/100 mL of beverages) and $\mathrm{pH}$ in infusions and concentrates of Buddleja scordioides treated with high-intensity pulsed electric fields (HiPEF).

\begin{tabular}{cccccc}
\hline \multirow{2}{*}{ Parameter } & \multicolumn{5}{c}{ Product } \\
\cline { 2 - 6 } & Infusion & Concentrate & HiPEF (800 kJ/kg) & HiPEF (1000 kJ/kg) & HiPEF (1100 kJ/kg) \\
\hline Solid content & $216 \pm 0.4$ & $802 \pm 7.0$ & $777 \pm 17$ & $771 \pm 14$ & $769 \pm 18$ \\
pH & $6.7 \pm 0.1$ & $6.0 \pm 0.00$ & $6.5 \pm 0.0$ & $6.5 \pm 0.0$ & $6.5 \pm 0.0$ \\
\hline
\end{tabular}

Data Mean \pm SD.

\subsection{Concentration Effects on Polyphenol Content}

The effect of concentration process on the content of phenolic acids of Buddleja scordioides, showed an increase of about $222 \%$ on the total phenolic acids content (Table 3). Concentrates showed statistical differences only with samples processed by HiPEF at $800 \mathrm{~kJ} / \mathrm{Kg}$. About flavonoids (Table 4) present in the system, it was observed a high increase of quercetin (i.e., in free phenolic form) in concentrates. A chromatogram of concentrate at $\lambda=280 \mathrm{~nm}$ is introduced as an example of all processing conditions experimented in the present study (Figure 1).

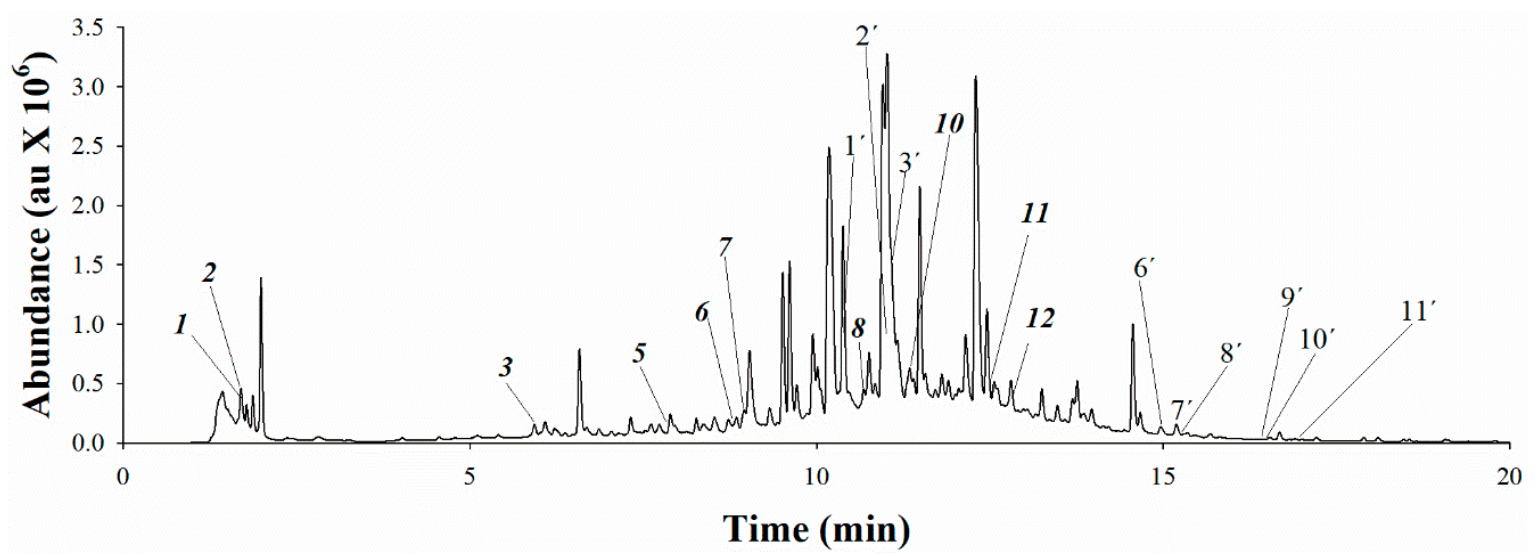

Figure 1. Chromatogram of concentrate of Buddleja scordioides infusion at $\lambda=280 \mathrm{~nm}$, as example of all processing conditions. Label numbers in italics with no quote marks indicate phenolic acids (see Table 3 for number codification of phenolic acids). Label numbers with quote marks indicate flavonoids (see Table 4 for number codification of flavonoids). 
Table 3. Phenolic acid profile on beverages from Buddleja scordioides under several HiPEF-processing conditions ( $\mu \mathrm{g} / \mathrm{mg}$ lyophilized beverage).

\begin{tabular}{|c|c|c|c|c|c|c|c|c|}
\hline No. & Chemical Compound & $\begin{array}{l}\text { Retention Time } \\
\text { (PDA) }\end{array}$ & Transitions & Infusion & Concentrate & $\begin{array}{l}\text { HiPEF } 800 \\
\text { kJ/kg }\end{array}$ & $\begin{array}{l}\text { HiPEF } 1000 \\
\text { kJ/kg }\end{array}$ & $\begin{array}{l}\text { HiPEF } 1100 \\
\text { kJ/kg }\end{array}$ \\
\hline 1. & Quinic acid & 1.66 & $191.20>85.06$ & $0.94 \pm 0.32^{a}$ & $1.41 \pm 0.31^{\mathrm{a}}$ & $2.71 \pm 0.12^{b}$ & $3.29 \pm 0.59^{b}$ & $2.14 \pm 0.06^{\mathrm{c}}$ \\
\hline 2. & Shikimic acid & 1.69 & $173.18>111.07$ & $0.66 \pm 0.12^{a}$ & $1.65 \pm 0.93 \mathrm{ab}$ & $1.05 \pm 0.06^{b}$ & $0.93 \pm 0.34^{b}$ & $0.43 \pm 0.01^{\mathrm{c}}$ \\
\hline 3. & Protocatechuic acid & 5.91 & $153.15>109.05$ & $\mathrm{Nd}$ & $0.54 \pm 0.05^{\mathrm{a}}$ & $N d$ & $\mathrm{Nd}$ & $\mathrm{Nd}$ \\
\hline 4. & Chlorogenic acid & 7.49 & $353.34>191.06$ & $N d$ & $N d$ & $3.945 \pm 0.61^{a}$ & $\mathrm{Nd}$ & $\mathrm{Nd}$ \\
\hline 5. & 4-Hydroxybenzoic acid & 7.88 & $137.04>93.05$ & $0.18 \pm 0.01^{\mathrm{a}}$ & $0.11 \pm 0.01^{b}$ & $N d$ & $N d$ & $N d$ \\
\hline 6. & Vanillic acid & 8.78 & $167.18>123.09$ & $\mathrm{Nd}$ & $0.02 \pm 0.02^{a}$ & $\mathrm{Nd}$ & Nd & $\mathrm{Nd}$ \\
\hline 7. & Caffeic acid & 8.91 & $179.19>135.08$ & $\mathrm{Nd}$ & $0.21 \pm 0.03 \mathrm{a}$ & $\mathrm{Nd}$ & $\mathrm{Nd}$ & $\mathrm{Nd}$ \\
\hline 8. & Coumaric acid & 10.76 & $163.24>119.08$ & $0.007 \pm 0.00^{\mathrm{a}}$ & $0.039 \pm 0.01^{b}$ & Nd & Nd & Nd \\
\hline 9. & Ellagic acid & 11.11 & $301.00>229.00$ & $N d$ & $\mathrm{Nd}$ & $0.35 \pm 0.07^{\mathrm{a}}$ & $1.06 \pm 0.07^{b}$ & $0.60 \pm 0.01^{\mathrm{c}}$ \\
\hline 10. & Ferulic acid & 11.37 & $193.24>134.04$ & $\mathrm{Nd}$ & $0.06 \pm 0.01^{\mathrm{a}}$ & $\mathrm{Nd}$ & Nd & Nd \\
\hline 11. & Rosmarinic acid & 12.52 & $359.28>161.04$ & $0.001 \pm 0.00^{\mathrm{a}}$ & $0.02 \pm 0.00^{b}$ & $0.001 \pm 0.00^{\mathrm{a}}$ & $0.001 \pm 0.00^{\mathrm{a}}$ & $0.001 \pm 0.00^{\mathrm{a}}$ \\
\hline 12. & Benzoic acid & 12.84 & $121.10>77.06$ & $0.062 \pm 0.00^{\mathrm{a}}$ & $0.05 \pm 0.00^{b}$ & $0.03 \pm 0.00^{c}$ & $0.03 \pm 0.00^{c}$ & $0.03 \pm 0.00^{\mathrm{c}}$ \\
\hline \multicolumn{4}{|c|}{ Total content } & $1.85 \pm 0.43^{\mathrm{a}}$ & $4.12 \pm 1.34^{\mathrm{bd}}$ & $8.09 \pm 0.87^{c}$ & $5.32 \pm 0.86^{d}$ & $3.2 \pm 0.09^{b}$ \\
\hline
\end{tabular}

Data Mean \pm SD, different letters in same raw indicate statistical differences $(p<0.05) ; N d$ is not detected.

Table 4. Flavonoid profile on beverages from Buddleja scordioides under several HiPEF-processing conditions ( $\mu \mathrm{g} / \mathrm{mg}$ lyophilized beverage).

\begin{tabular}{|c|c|c|c|c|c|c|c|c|c|}
\hline No. & Chemical Compound & Rt (PDA) min & $\lambda \max \mathrm{nm}$ & Transitions & Infusion & Concentrate & $\begin{array}{c}\text { HiPEF } 800 \\
\text { kJ/kg }\end{array}$ & $\begin{array}{l}\text { HiPEF } 1000 \\
\text { kJ/kg }\end{array}$ & $\begin{array}{l}\text { HiPEF } 1100 \\
\text { kJ/kg }\end{array}$ \\
\hline 1. & Rutin & 10.34 & 353.5 & $609.40>301.15$ & $\operatorname{tr}$ & $0.060 \pm 0.02^{\mathrm{a}}$ & $0.01 \pm 0.00^{b}$ & $0.003 \pm 0.0^{c}$ & $0.003 \pm 0.0^{\mathrm{c}}$ \\
\hline 2. & Quercetin-3-O- $\beta$-glucuronide & 11.05 & 353.5 & $477.26>300.42$ & $t r$ & $0.036 \pm 0.00^{\mathrm{a}}$ & tr & $0.025 \pm 0.0^{\mathrm{b}}$ & $0.025 \pm 0.0^{\mathrm{b}}$ \\
\hline 3. & Isoquercitrin & 11.09 & 353.5 & $463.36>300.42$ & $\operatorname{tr}$ & $0.204 \pm 0.02^{\mathrm{a}}$ & $0.24 \pm 0.01^{\mathrm{a}}$ & $0.19 \pm 0.01^{b}$ & $0.22 \pm 0.00^{\mathrm{a}}$ \\
\hline 4. & Naringin & 11.88 & 282.5 & $579.32>151.02$ & $\operatorname{tr}$ & tr & tr & tr & Nd \\
\hline 5. & Neohesperidin & 12.34 & 352.5 & $609.40>301.15$ & $\operatorname{tr}$ & $\operatorname{tr}$ & $\operatorname{tr}$ & $t r$ & $\operatorname{Tr}$ \\
\hline 6. & Luteolin & 14.93 & 347.5 & $285.21>133.04$ & $\operatorname{tr}$ & $0.34 \pm 0.04^{\mathrm{a}}$ & tr & tr & $\operatorname{Tr}$ \\
\hline 7. & Quercetin & 15.14 & 370.5 & $301.20>151.02$ & $t r$ & $0.86 \pm 0.18^{\mathrm{a}}$ & $0.007 \pm 0.0^{b}$ & $0.004 \pm 0.0^{b}$ & $0.008 \pm 0.0^{b}$ \\
\hline 8. & Acacetin & 15.20 & 333.5 & $283.23>268.10$ & $t r$ & $0.15 \pm 0.04^{b}$ & tr & tr & $\operatorname{Tr}$ \\
\hline 9. & Naringenin & 16.34 & 288.5 & $271.28>119.06$ & $t r$ & $0.02 \pm 0.01^{\mathrm{a}}$ & $0.02 \pm 0.02^{\mathrm{a}}$ & $0.005 \pm 0.0^{b}$ & $0.002 \pm 0.0^{\mathrm{b}}$ \\
\hline 10. & Apigenin & 16.45 & 335.5 & $269.27>117.04$ & $\operatorname{tr}$ & $0.07 \pm 0.02^{b}$ & tr & tr & $\mathrm{Nd}$ \\
\hline 11. & Kaempferol & 16.93 & 363.5 & $285.22>151.02$ & $t r$ & $0.005 \pm 0.00^{\mathrm{a}}$ & $t r$ & tr & $0.002 \pm 0.0^{\mathrm{b}}$ \\
\hline \multicolumn{5}{|c|}{ Total content } & tr & $1.74 \pm 0.27^{\mathrm{a}}$ & $0.28 \pm 0.03^{b}$ & $0.23 \pm 0.02^{b}$ & $0.27 \pm 0.00^{b}$ \\
\hline
\end{tabular}

Data Mean \pm SD, different letters in same raw indicate statistical differences $(p<0.05)$. $t$ indicates trace; $N d$, not detected. 


\subsection{Antioxidant Activity}

Antioxidant assay data for infusions and concentrates are shown in Table 5. DPPH data show a minor increase on antioxidant capacity of concentrates in comparison to the infusions (around $4 \%$ ). All processed samples showed lower inhibition percentage of NO than untreated infusions, independently of the higher concentration of polyphenolic compounds (Table 5).

Table 5. Antioxidant capacity.

\begin{tabular}{ccc}
\hline Experimental Sample & DPPH (\%) & \% Inhibition of NO \\
\hline Control NO & $28.5 \pm 3.2$ & $3.1 \pm 0.01$ \\
Control DPPH & $73.2 \pm 0.1^{\mathrm{a}}$ & $38.48 \pm 7.9^{\mathrm{a}}$ \\
$\quad$ Infusion & $74.8 \pm 0.9^{\mathrm{b}}$ & $27.85 \pm 3.6^{\mathrm{ac}}$ \\
Concentrates & $65.6 \pm 0.3^{\mathrm{c}}$ & $23.10 \pm 0.4^{\mathrm{b}}$ \\
Concentrates treated by & $71.4 \pm 0.3^{\mathrm{d}}$ & $26.89 \pm 1.7^{\mathrm{c}}$ \\
HiPEF 800 & $63.8 \pm 0.2^{\mathrm{e}}$ & $24.21 \pm 0.1^{\mathrm{d}}$ \\
\hline Concentrates 1000 & & \\
\hline
\end{tabular}

Data Mean \pm SD, different letters in same raw indicate statistical differences $(p<0.05)$.

\section{Discussion}

As expected, solid content present in concentrated infusions was higher than observed in infusions; this behavior is result of the water evaporation occurred into the falling film evaporator. No statistical differences were observed between concentrates and concentrates treated by HiPEF in solid content.

Observed changes in $\mathrm{pH}$ of concentrates and HiPEF-treated concentrated beverages could be explained by the evaporation process that involves heating; thus, the herbal infusion under these conditions could show hydrolysis and/or oxidation of their chemical components. Also, several reports indicate that the use of HiPEF lowers the $\mathrm{pH}$ value of samples; however, this change is function of the position of sample into the HiPEF treatment chamber [32].

About the phenolic acids, it has been reported [33] an increase of chlorogenic acid in tomato juice processed by HiPEF, however, the increase reported was around $30 \%$ at only one condition of the HiPEF treatment. In the present work, chlorogenic only was present at the lower condition of HiPEF processing $(800 \mathrm{~kJ} / \mathrm{kg})$. Phenolic acids have not been studied on their chemical stability as well as related anthocyanin content. However, derivatives of p-coumaric and ferulic acids are commonly very sensitive to light; on the other hand, caffeic acids derivatives are fairly stable. In general, $\mathrm{O}$-acylglucoses of hydroxycinnamic acids (HCAs) are the most labile type of derivatives of this class. $O$-acylglucoses and $O$-acylquinic acids of HCAs are degraded by the loss of sugar or quinic acid moieties, resulting in free HCAs [34]. In the present experiment, this phenomenon could produce and increase in the concentration of free HCAs, especially when the herbal infusion was concentrated and processed. It is interesting to note that the use of HiPEF $(\geq 800 \mathrm{~kJ} / \mathrm{kg})$ drops the amount of HCAs to similar levels as the observed in the infusions. Additionally, it should be highlighted that the total amount of phenolic acids was similar for concentrates and HiPEF $800 \mathrm{~kJ} / \mathrm{kg}$ and HiPEF $1100 \mathrm{~kJ} / \mathrm{kg}$, thus under several circumstances and without proper chemical evaluation, prompt conclusions could be wrong.

The observed increase of flavonoids in concentrates could be related to degradation products resulting from the oxidation of quercetin in aqueous solutions under heating. Also, it has led to protocatechuic acid in a possible pathway; although nucleophilic addition products of quercetin are also present [16]. Therefore, a second reaction pathway must take place in which quercetin is oxidized to quinic acid or their derivatives (pathway II).

The increase on free quercetin in concentrates could be related with the fact that phenolic compounds occur in both soluble free and insoluble-bound forms. Most of the soluble phenolics are localized in the vacuoles of plant cells where they are trapped. On the other hand, insoluble-bound 
phenolics are localized into the cell wall matrix of plant cells occluded among cellulose and lignin molecules.

However, the use of hydro thermal processes has been used to obtain insoluble-bound phenolics [35]. The use of falling film evaporator could improve the extraction of insoluble-bound phenolics by the combined action of temperature and pressure. In addition, the solid content present in the infusion feed into the falling film evaporator indicates high presence of insoluble-bound phenolics in Buddleja scordioides. Besides, a high stability of quercetin glycosides as rutin or isoquercetrin is observed too. Several reports indicate that the relative high stability of rutin in comparison to quercetin is related with its chemical structure [36]. Buchner et al. reported [16] that this behavior could be attributed to the prevention of carbanion formation because of the glycosylation of the 3-hydroxyl group in the flavonoid C-ring.

A possible explanation of the behavior could be related with the use of liquid water into the falling film evaporator, which is subjected to high pressure to achieve temperatures higher than the boiling point without changing phase [37]. The keys to improve extractions are related with the increase of water temperature above the boiling point, which results in significant lower values of dielectric constants of subcritical water, becoming similar to that of organic solvents [38]. According to data reported previously [39], the extraction of polyphenols by subcritical water is dependent on the temperature (i.e., higher yields at higher temperatures) and time, however longer times and higher temperatures could diminish the yield by thermal degradation of the compounds.

Usually the use of falling film evaporator produces steam; however, sometimes condenser pressure could improve conditions, producing subcritical water (i.e., by the combined high pressure and high temperature conditions obtained at the condenser). The vacuum pump is the responsible to extract the steam generated by the contact between heated wall and the feeding flow; thus, if the heat is high and the vacuum is not sufficient, pressure increases (and inner temperature too) up to certain limits depending on the vacuum level. Therefore, the feeding flow reaches subcritical conditions that may enhance the extraction of bioactives in some herbal samples as Buddleja.

About the specific effect of HiPEF on flavanols, the amount of quercetin present in the samples treated with HiPEF showed a drastic reduction in comparison to the concentrates of Buddleja infusions. This is not in accordance with other reports [17], which showed the effect of the high-intensity pulsed electric fields (HIPEF) process, causing no reduction on quercetin and kaempferol contents in strawberry juices. However, Bi et al. [40] reported that the use of HiPEF on the chemical stability of some bioactive compounds is dependent on the pulse rise time (PRT), having higher degradations when lower PRTs are applied. Also, Buchner et al. [16] reported that higher chemical instability of quercetin is observed at aqueous solution with $\mathrm{pH}$ nearby to neutral conditions.

The small increase on antioxidant activity (i.e., in DPPH test) observed in the concentrates could be related with the minor increase in polyphenolic content. It is interesting to note that slightly lower antioxidant capacities measured by DPPH were obtained for concentrates treated by HiPEF in comparison to infusions and concentrates and that this decline in antioxidant activity could not be related to the lower amount of phytochemical compounds detected in HiPEF concentrates, because all HiPEF treatments showed higher content of polyphenolic compounds. In this sense, Odriozola-Serrano et al. [17] reported reductions in antioxidant capacity of tomato juice treated by HiPEF. Also, Sánchez-Vega et al. [41] reported reduction on antioxidant capacity of broccoli juice associated to losses of some antioxidant compounds during HiPEF processing. However, a higher number of compounds were quantified in the concentrates in comparison with the HiPEF treatments at 800,1000 and $1100 \mathrm{~kJ} / \mathrm{kg}$; consequently, there is a clear relationship between more chemical diversity in polyphenol compounds and higher antioxidant capacity.

Results obtained for inhibition of $\mathrm{NO}$ are interesting because all processed samples showed lower inhibition percentage of NO than untreated infusions, independently of the higher concentration of polyphenolic compounds. Nevertheless, no differences were observed between infusion concentrates and concentrated samples treated at $1000 \mathrm{~kJ} / \mathrm{kg}$. On the other hand, lower values of NO inhibition 
were observed at 800 and $1100 \mathrm{~kJ} / \mathrm{kg}$. These results indicate that other chemical compounds present in salvilla infusions are important to correlate with antioxidant capacities as the verbascosides. Therefore, the use of HiPEF may be useful to treat concentrates once the proper processing conditions are set.

\section{Conclusions}

The use of falling film evaporator under several circumstances (i.e., low vacuum) increases the amount of flavonols (i.e., quercetin) and their antioxidant capacity in comparison with the untreated infusions. However, the use of HiPEF treatment diminishes flavonoids concentration but increases the amount of free phenolic acids, producing a slightly minor antioxidant capacity. Conversely, the use of HiPEF to process concentrates of Buddleja infusions at $1000 \mathrm{~kJ} / \mathrm{kg}$ and $1100 \mathrm{~kJ} / \mathrm{kg}$ show a similar profile on phenolic acids between HiPEF-treated beverages and concentrates, showing that the use of HiPEF may be a promising technology for the processing practices of herbal infusions.

Author Contributions: Conceptualization, J.A.G.-I.; Formal analysis, N.E.R.-G.; Funding acquisition, J.A.G.-I.; Investigation, J.O.D.-R.; Methodology, C.I.G.-G. and M.R.M.-J.; Project administration, J.A.G.-I.; Resources and experimentation, A.V.-F. and A.R.-R.; Validation, N.E.R.-G.; Writing-discussion \& editing, R.F.G.-L.

Funding: This research was partially funded by Tecnológico Nacional de Mexico, grant number TecNM 6074.17-P and CONACyT grant numbers 280172 and 224651.

Acknowledgments: Author J.O.D.R. acknowledges scholarship from the National Council for Science and Technology (CONACYT). Authors recognize permission of ITESM for using their HiPEF facilities.

Conflicts of Interest: The authors declare no conflict of interest.

\section{References}

1. Whitehead, J. Functional drinks containing herbal extracts. In Chemistry and Technology of Soft Drinks and Fruit Juices; John Wiley \& Sons Ltd.: Now York, NY, USA, 2016; pp. 225-257.

2. Rodrigues, M.J.; Neves, V.; Martins, A.; Rauter, A.P.; Neng, N.R.; Nogueira, J.M.; Custódio, L. In vitro antioxidant and anti-inflammatory properties of Limonium algarvense flowers' infusions and decoctions: A comparison with green tea (Camellia sinensis). Food Chem. 2016, 200, 322-329. [CrossRef] [PubMed]

3. Atoui, A.K.; Mansouri, A.; Boskou, G.; Kefalas, P. Tea and herbal infusions: their antioxidant activity and phenolic profile. Food Chem. 2005, 89, 27-36. [CrossRef]

4. Farzaneh, V.; Carvalho, I.S. A review of the health benefit potentials of herbal plant infusions and their mechanism of actions. Ind. Crop. Prod. 2015, 65, 247-258. [CrossRef]

5. Tachakittirungrod, S.; Okonogi, S.; Chowwanapoonpohn, S. Study on antioxidant activity of certain plants in Thailand: Mechanism of antioxidant action of guava leaf extract. Food Chem. 2007, 103, 381-388. [CrossRef]

6. Arrieta-Baez, D.; de Esparza, R.R.; Jiménez-Estrada, M. Mexican plants used in the salmonellosis treatment. In Salmonella-A Diversified Superbug; Kumar, Y., Ed.; InTech Open: London, UK, 2012; Available online: http:/ /www.intechopen.com/books/salmonella-a-diversifiedsuperbug/mexican-plants-used-inthe-salmonellosis-treatment (accessed on 20 July 2018).

7. Avila-Acevedo, J.; Castañeda, C.M.C.; Benitez, F.J.C.; Durán, D.A.; Barroso, V.R.; Martínez, C.G.; de Vivar, A.R. Photoprotective activity of Buddleja scordioides. Fitoterapia 2005, 76, 301-309. [CrossRef] [PubMed]

8. Houghton, P.J.; Hylands, P.J.; Mensah, A.Y.; Hensel, A.; Deters, A.M. In vitro tests and ethnopharmacological investigations: wound healing as an example. J. Ethnopharmacol. 2005, 100, 100-107. [CrossRef] [PubMed]

9. Cortés, A.R.; Delgadillo, A.J.; Hurtado, M.; Domínguez-Ramírez, A.M.; Medina, J.R.; Aoki, K. The antispasmodic activity of Buddleja scordioides and Buddleja perfoliata on isolated intestinal preparations. Biol. Pharm. Bull. 2006, 29, 1186-1190. [CrossRef] [PubMed]

10. Sánchez-Moreno, C.; Plaza, L.; Elez-Martínez, P.; De Ancos, B.; Martín-Belloso, O.; Cano, M.P. Impact of high pressure and pulsed electric fields on bioactive compounds and antioxidant activity of orange juice in comparison with traditional thermal processing. J. Agric. Food Chem. 2005, 53, 4403-4409. [CrossRef] [PubMed]

11. Charles-Rodríguez, A.V.; Nevárez-Moorillón, G.V.; Zhang, Q.H.; Ortega-Rivas, E. Comparison of thermal processing and pulsed electric fields treatment in pasteurization of apple juice. Food Bioprod. Process. 2007, 85, 93-97. [CrossRef] 
12. Barba, F.J.; Esteve, M.J.; Frigola, A. Ascorbic acid is the only bioactive that is better preserved by high hydrostatic pressure than by thermal treatment of a vegetable beverage. J. Agric. Food Chem. 2010, 58, 10070-10075. [CrossRef] [PubMed]

13. Arancibia-Avila, P.; Namiesnik, J.; Toledo, F.; Werner, E.; Martinez-Ayala, A.L.; Rocha-Guzmán, N.E.; Gorinstein, S. The influence of different time durations of thermal processing on berries quality. Food Control 2012, 26, 587-593. [CrossRef]

14. Ranilla, L.G.; Genovese, M.I.; Lajolo, F.M. Isoflavones and antioxidant capacity of Peruvian and Brazilian lupin cultivars. J. Food Comp. Anal. 2009, 22, 397-404. [CrossRef]

15. Murakami, M.; Yamaguchi, T.; Takamura, H.; Matoba, T. Change in the radical-scavenging activity of quercetin and epigallocatechin gallate during heat treatment. J. Home Econ. Jpn. 2004, 55, 213-217.

16. Buchner, N.; Krumbein, A.; Rohn, S.; Kroh, L.W. Effect of thermal processing on the flavonols rutin and quercetin. Rapid Comm. Mass. Spec. 2006, 20, 3229-3235. [CrossRef] [PubMed]

17. Odriozola-Serrano, I.; Soliva-Fortuny, R.; Gimeno-Añó, V.; Martín-Belloso, O. Modeling changes in health-related compounds of tomato juice treated by high-intensity pulsed electric fields. J. Food Eng. 2008, 89, 210-216. [CrossRef]

18. Jiménez-Zamora, A.; Delgado-Andrade, C.; Rufián-Henares, J.A. Antioxidant capacity, total phenols and color profile during the storage of selected plants used for infusion. Food Chem. 2016, 199, 339-346. [CrossRef] [PubMed]

19. Arthur, H.; Joubert, E.; De Beer, D.; Malherbe, C.J.; Witthuhn, R.C. Phenylethanoid glycosides as major antioxidants in Lippia multiflora herbal infusion and their stability during steam pasteurisation of plant material. Food Chem. 2011, 127, 581-588. [CrossRef] [PubMed]

20. Gancel, A.L.; Feneuil, A.; Acosta, O.; Pérez, A.M.; Vaillant, F. Impact of industrial processing and storage on major polyphenols and the antioxidant capacity of tropical highland blackberry (Rubus adenotrichus). Food Res. Intl. 2011, 44, 2243-2251. [CrossRef]

21. Toepfl, S.; Heinz, V.; Knorr, D. High intensity pulsed electric fields applied for food preservation. Chem. Eng. Proc. Process. Intensification 2007, 46, 537-546. [CrossRef]

22. Toepfl, S.; Heinz, V. Pulsed electric field assisted extraction-A case study. In Nonthermal Processing Technologies for Food; Blackwell Pub.: New York, NY, USA, 2011; pp. 190-200.

23. MacGregor, S.J.; Farish, O.; Fouracre, R.; Rowan, N.J.; Anderson, J.G. Inactivation of pathogenic and spoilage microorganisms in a test liquid using pulsed electric fields. IEEE Trans. Plasma Sci. 2000, 28, 144-149. [CrossRef]

24. Raso, J.; Calderón, M.L.; Góngora, M.; Barbosa-Cánovas, G.V.; Swanson, B.G. Inactivation of Zygosaccharomyces bailii in fruit juices by heat, high hydrostatic pressure and pulsed electric fields. J. Food Sci. 1998, 63, 1042-1044. [CrossRef]

25. Raso, J.; Calderón, M.L.; Góngora, M.; Barbosa-Cánovas, G.; Swanson, B.G. Inactivation of mold ascospores and conidiospores suspended in fruit juices by pulsed electric fields. LWT-Food Sci. Technol. 1998, 31, 668-672. [CrossRef]

26. Timmermans, R.A.H.; Mastwijk, H.C.; Knol, J.J.; Quataert, M.C.J.; Vervoort, L.; Van der Plancken, I.; Matser, A.M. Comparing equivalent thermal, high pressure and pulsed electric field processes for mild pasteurization of orange juice. Part I: Impact on overall quality attributes. Innov. Food Sci. Emegr. Technol. 2011, 12, 235-243. [CrossRef]

27. Zhao, W.; Yang, R.; Lu, R.; Wang, M.; Qian, P.; Yang, W. Effect of PEF on microbial inactivation and physical-chemical properties of green tea extracts. LWT-Food Sci. Technol. 2008, 41, 425-431. [CrossRef]

28. Vazquez-Cabral, D.; Valdez-Fragoso, A.; Rocha-Guzman, N.E.; Moreno-Jimenez, M.R.; Gonzalez-Laredo, R.F.; Morales-Martinez, P.S.; Gallegos-Infante, J.A. Effect of pulsed electric field (PEF)-treated kombucha analogues from Quercus obtusata infusions on bioactives and microorganisms. Innov. Food Sci. Emerg. Technol. 2016, 34, 171-179. [CrossRef]

29. Rocha-Guzmán, N.E.; Gallegos-Infante, J.A.; González-Laredo, R.F.; Reynoso-Camacho, R.; Ramos-Gómez, M.; Garcia-Gasca, T.; Lujan-García, B.A. Antioxidant activity and genotoxic effect on HeLa cells of phenolic compounds from infusions of Quercus resinosa leaves. Food Chem. 2009, 115, 1320-1325. [CrossRef]

30. Brand-Williams, W.; Cuvelier, M.E.; Berset, C.L.W.T. Use of a free radical method to evaluate antioxidant activity. LWT-Food Sci. Technol. 1995, 28, 25-30. [CrossRef] 
31. Balakrishnan, N.; Panda, A.B.; Raj, N.R.; Shrivastava, A.; Prathani, R. The evaluation of nitric oxide scavenging activity of Acalypha indica Linn root. Asian J. Res. Chem. 2009, 2, 148-150.

32. Meneses, N.; Jaeger, H.; Knorr, D. pH-changes during pulsed electric field treatments-Numerical simulation and in situ impact on polyphenoloxidase inactivation. Innov. Food Sci. Emerg. Technol. 2011, 12, 499-504. [CrossRef]

33. Vallverdú-Queralt, A.; Odriozola-Serrano, I.; Oms-Oliu, G.; Lamuela-Raventós, R.M.; Elez-Martínez, P.; Martin-Belloso, O. Changes in the polyphenol profile of tomato juices processed by pulsed electric fields. J. Agric. Food Chem. 2012, 60, 9667-9672. [CrossRef] [PubMed]

34. Makila, L.; Laaksonen, O.; Alanne, A.L.; Kortesniemi, M.; Kallio, H.; Yang, B. Stability of hydroxycinnamic acid derivatives, flavonol glycosides and anthocyanins in black currant juice. J. Agric. Food Chem. 2016, 64, 4584-4598. [CrossRef] [PubMed]

35. Yeo, J.; Shahidi, F. Effect of hydrothermal processing on changes of insoluble-bound phenolics of lentils. J. Funct. Foods 2017, 38, 716-722. [CrossRef]

36. Makris, D.P.; Rossiter, J.T. Quercetin and rutin (quercetin 3-O-rhamnosylglucoside) thermal degradation in aqueous media under alkaline conditions. Spec. Publ.-R. Soc. Chem. 2000, 248, 216-238.

37. Zakaria, S.M.; Kamal, S.M.M. Subcritical water extraction of bioactive compounds from plants and algae: applications in pharmaceutical and food ingredients. Food Eng. Rev. 2016, 8, 23-34. [CrossRef]

38. Miller, D.J.; Hawthorne, S.B.; Gizir, A.M.; Clifford, A. Solubility of polycyclic aromatic hydrocarbons in subcritical water from $298 \mathrm{~K}$ to 498 K. J. Chem. Eng. Data 1998, 43, 1043-1047. [CrossRef]

39. Lee, J.H.; Ko, M.J.; Chung, M.S. Subcritical water extraction of bioactive components from red ginseng (Panax ginseng CA Meyer). J. Supercrit. Fluids 2018, 133, 177-183. [CrossRef]

40. Bi, X.; Liu, F.; Rao, L.; Li, J.; Liu, B.; Liao, X.; Wu, J. Effects of electric field strength and pulse rise time on physicochemical and sensory properties of apple juice by pulsed electric field. Innov. Food Sci. Emerg. Technol. 2013, 17, 85-92. [CrossRef]

41. Sánchez-Vega, R.; Elez-Martínez, P.; Martín-Belloso, O. Effects of high-intensity pulsed electric fields processing parameters on the chlorophyll content and its degradation compounds in broccoli juice. Food Bioprocess Technol. 2014, 7, 1137-1148. [CrossRef]

(C) 2018 by the authors. Licensee MDPI, Basel, Switzerland. This article is an open access article distributed under the terms and conditions of the Creative Commons Attribution (CC BY) license (http:/ / creativecommons.org/licenses/by/4.0/). 